\title{
FINE NEEDLE ASPIRATION CYTOLOGY OF SALIVARY GLAND LESIONS AND ITS DIAGNOSTIC PITFALLS - A TERTIARY CARE CENTRE EXPERIENCE FROM NORTH EAST INDIA
}

\author{
Asitava Deb Roy¹, Muktanjalee Deka², Umesh Chandra Dutta ${ }^{3}$.
}

1. Assistant Professor, Department of Pathology, Sikkim Manipal Institute of Medical Sciences.

2. Associate Professor, Department of Pathology, Gauhati Medical College.

3. Professor \& HOD, Department of Pathology, Gauhati Medical College.

\section{CORRESPONDING AUTHOR}

Dr. Asitava Deb Roy,

Department of Pathology,

Sikkim Manipal Institute of Medical Sciences,

5th Mile, Tadong, Gangtok,

East Sikkim- 737102.

Email- asitavadr@gmail.com

\section{HOW TO CITE THIS ARTICLE:}

Asitava Deb Roy, Muktanjalee Deka, Umesh Chandra Dutta. "Fine Needle Aspiration Cytology of Salivary Gland Lesions and its Diagnostic Pitfalls - A Tertiary Care Centre Experience from North East India". Journal of Evolution of Medical and Dental Sciences 2013; Vol2, Issue 26, July 1; Page: 4832-4839.

ABSTRACT: - INTRODUCTION: Fine needle aspiration cytology (FNAC) of salivary gland lesions has become very popular as a pre-operative diagnostic tool. However, in some instances the final histology of these lesions differs from the FNAC result. OBJECTIVE: To determine the diagnostic accuracy of FNAC in salivary gland lesions and identify the salivary gland FNA cases having discordant histological diagnosis so that most common diagnostic pitfalls can be avoided. MATERIAL AND METHODS: Sixty four salivary gland FNAC cases from January 2009 to December 2010 were retrospectively reviewed to identify the cytological characteristics that may have contributed to this discrepancy. Only 44 cases could be correlated histopathologically. RESULTS: Of the 64 cases analysed cytologically, 4 smears turned out to be unsatisfactory for evaluation, hence only rest 60 smears were evaluated. Out of the 32 cases which were given as cytologically benign, 28 were confirmed as benign on histology, while 04 cases turned out as malignant on histology. Of the 12 cases which were cytologically malignant, 2 turned out to be benign on histology. Taking histology as the "gold standard", the following data were obtained: specificity $92.8 \%$, sensitivity $69.8 \%$, diagnostic accuracy $84.5 \%$, positive predictive value $83 \%$ and negative predictive value $83 \%$. CONCLUSION: Despite inadequate samples obtained in some cases, FNAC should be done in the preoperative diagnosis of salivary gland lesions as it offers high diagnostic accuracy and specificity and an acceptable sensitivity.

KEYWORDS: FNAC, diagnostic pitfalls, salivary glands lesions

INTRODUCTION: Fine needle aspiration cytology (FNAC) has become a well-established technique in the preoperative diagnosis of head and neck lesions including the major and minor salivary glands. It is one of the most valuable tests available in the initial assessment of the patient who 


\section{ORIGINAL ARTICLE}

presents with a mass in the head and neck region or where a recurrence is suspected after previous treatment [1]. Its popularity comes from the ease of performance, low morbidity and rapid diagnosis. It has some edge over an incisional biopsy and frozen section. FNAC is a simple, quick, useful and reliable procedure. Wide sampling of the lump is possible. This procedure takes only 5-10 minutes and result could be available after 15-20 minutes [2]. However, a highly qualified cytologist and a well-trained procurer of specimen are required for correct interpretation.

The aims and objectives of the present study were:

1. To correlate the FNAC diagnosis of salivary gland swellings with histopathology.

2. To find out the sensitivity, specificity and diagnostic accuracy of FNAC of salivary gland lesions in our institution.

3. To investigate the discordant cases in detail to establish the source of the errors.

MATERIALS AND METHODS: The study was conducted over a two years period from January 2009 to December 2010. The fine needle aspiration biopsies (FNAB) were obtained in the Pathology outpatient-department. Prior to FNAC, the patients were examined in detail, which included the recording of their pertinent clinical history and significant clinical findings. Relevant investigations were carried out as per requirements. After a brief explanation of the technique, an informed consent of the patient was obtained. FNA was done using a 23 gauge needle fitted to a $10 \mathrm{ml}$ disposable syringe. Both air dried and wet fixed (in absolute alcohol) smears were made and stained with May Grunwald Giemsa (MGG)/ Papanicolaou (Pap) respectively, following standard protocols. The excised biopsy samples were obtained in $10 \%$ formalin and routinely processed and stained with Haematoxylin and Eosin following standard protocols. A total of 64 (sixty four) cases had undergone preoperative FNAC of which only 44 (forty four) cases could be correlated with their histopathological findings. The definitive histopathologic report was the gold standard diagnosis against which FNAC was compared. Sensitivity for the presence of malignancy (true positive/true positive + false negative), specificity for absence of malignancy (true negative/true negative + false positive), positive predictive value (PPV) (true positive/true positive + false positive), negative predictive value (NPV)(true negative/true negative + false negative)and accuracy of FNAC (true positive + true negative/total) were calculated and compared with other studies.

RESULTS AND OBSERVATIONS: Among the total 64 patients who had undergone fine needle aspiration (FNA), 31 were males and 33 were females (M: F ratio = 0.9:1). Parotid gland (75\%) was the commonest site aspirated, followed by submandibular gland $(22 \%)$ and minor salivary gland (3\%).

Four smears turned out to be unsatisfactory for evaluation due to presence of blood cells only. Rest 60 smears were evaluated and divided into two groups: non-neoplastic and neoplastic lesions. The neoplastic lesions were divided into benign and malignant category. Five benign cases which could not be typed on cytology were designated as 'benign neoplastic lesion' and advised excision. The cytological diagnoses given for these cases are detailed in Table No.1. The most common diagnosis amongst the benign lesions was pleomorphic adenoma and adenoid cystic carcinoma was the most common malignant diagnosis.

Cyto-histopathological correlation was possible in 44 cases. Out of the thirty two cases which were given as cytologically benign, 28 were confirmed as benign on histology, while 04 cases turned 


\section{ORIGINAL ARTICLE}

out as malignant. Of the 12 cases which were cytologically malignant, 2 turned out to be benign on histology.

Two cases of pleomorphic adenoma turned out to be adenoid cystic carcinoma and 2 cases diagnosed as 'benign neoplastic' on cytology turned out to be acinic cell carcinoma. On the other hand 1case of adenoid cystic carcinoma turned out to be pleomorphic adenoma and 1 case of mucoepidermoid carcinoma turned out to be retention mucus cyst.

Therefore, taking histology as the "gold standard", the number of false positive cases were two and false negative cases were four. Hence, the following data were obtained: specificity $92.8 \%$, sensitivity $69.8 \%$, diagnostic accuracy $84.5 \%$, positive predictive value $83 \%$ and negative predictive value $83 \%$.

DISCUSSION: Salivary gland FNAs are very common in pathology practices but often present several interpretation challenges. Different studies have documented the accuracy and limitation of salivary gland FNAC. The overall accuracy has been reported to be $82 \%$ to $94 \%$ in distinguishing benign from malignant lesions. FNAC also has a reported sensitivity of $65 \%$ to $85 \%$ and a specificity of $90 \%$ to $100 \%$ ([3], [4], [5], [6]). Table 2 shows that the sensitivity, specificity and accuracy of FNA diagnosis of salivary glands obtained in this study is comparable with the data obtained in similar studies done previously.

Few pitfalls could not be avoided. The false negative cases were:

1. Two cases of adenoid cystic carcinoma; misdiagnosed on cytology as pleomorphic adenoma because the smears were hypocellular and did not show prominent hyaline globules (although myxoid stromal fragments were present). The cells showed little atypia and there were no naked nuclei seen (Figure 1).

The distinction between pleomorphic adenoma and adenoid cystic carcinoma is clinically important. The stromal component does not always help. Hyaline stromal globule may be seen in pleomorphic adenoma and a fibrillar stroma can be seen in adenoid cystic carcinoma. Thus the differential diagnosis between these tumors can therefore not be based solely on the stromal component. Cytological detail should be carefully examined i.e. scanty cytoplasm, high nucleus to cytoplasm ratio, naked nuclei, nuclear moulding and nuclear hyperchromasia to avoid errors in the cytological diagnosis of adenoid cystic carcinoma [7].

2. Two cases of well differentiated acinic cell carcinoma; misdiagnosed as benign neoplastic lesion as the smears were hypocellular and there were no overt features of malignancy in the cytology slide (Figure 2).

Classically, the aspirates of acinic cell carcinoma are highly cellular, composed of fragments and associated cells that are larger than benign ones, a characteristic feature is the presence of numerous dissociated naked tumor cell nuclei. When the classic features of acinic cell carcinoma are present, its diagnosis may not be difficult. However, problems arise when overlapping features are present [7]. The nuclear features of normal (non-neoplastic) acinar cells are quite similar to those observed in acinic cell carcinoma, the only subtle differences is the smaller size of the non-neoplastic acinar cell nuclei as compared with neoplastic acinar one and the basally oriented nuclei in normal cells, whereas in acinic cell carcinoma they are often centrally located. The most helpful diagnostic feature in the differential diagnosis is the low power arrangement of non-neoplastic salivary gland in a 


\section{ORIGINAL ARTICLE}

lobulated, rosette-like and acinar pattern, features which are readily can be observed in tissue sections rather than cytologic smears [8].

The discordance mainly occurred because of trying to interpret smears which were hypocellular. This led to more of false negative cases, giving a low sensitivity. However, the guiding principle of any cytologist should always be to reduce the false negative cases to absolute minimum, so that the confidence of the referring specialists, in FNAC, is boosted and more importantly, no patient with malignancy is falsely reassured ([9],[15]). This can be achieved by making multiple passes through different sites of the lesion and checking the adequacy of smears in the aspiration room itself using some rapid stains viz. Diff Quik. This will reduce the number of hypocellular smears reaching the cytopathologist for evaluation. Although multiple aspirations were done but rapid stains for checking adequacy were not available for the study. Moreover, frozen sections should be considered in cases where cytological diagnosis is benign in cases of clinically suspicious mass [10].

The false positive cases were:

1. One case of cellular pleomorphic adenoma which was over diagnosed as adenoid cystic carcinoma due to high cellularity, mild cellular atypia and presence of prominent stromal component (Figure 3).

2. One case of mucus retention cyst was over diagnosed as mucoepidermoid carcinoma due to presence of mucus debris and few squamous cells mimicking intermediate cells (Figure 4).

The anomalies occurred because the features of atypia were overlooked. Careful evaluation under oil immersion objective to study the subtle nuclear details and discussion with experienced colleagues in case of difficult cases may prove beneficial [2].

Table 3 shows the FNAC cases with discordant diagnoses.

Although fine needle aspiration cytology (FNAC) is usually done routinely, most salivary gland tumours, with the exception of lymphomas, need to be excised even if the FNAC is reported as benign. There are a number of reasons for this. Firstly, FNAC is not $100 \%$ accurate, and the accuracy varies according to the experience of the cytopathologist [11]. Secondly, the commonest benign tumour is a pleomorphic adenoma which has the potential to undergo malignant transformation in a long-standing case. Thirdly, many patients may also want the tumour removed for cosmetic reasons [12]. Despite the drawbacks, FNAC is still useful and usually forms part of the diagnostic work-up. There are 2 main reasons for this. Firstly, non-neoplastic lesions can sometimes be confidently diagnosed e.g. tuberculosis. In these cases, surgery can be avoided altogether and patients treated accordingly. Secondly, if cytology diagnoses a malignancy, which is highly specific ([11], [12], [13], [14], [15]), it helps in the surgical planning and enhances better pre-operative counseling [12].

CONCLUSION: Despite inadequate samples obtained in some cases, the technique of FNAB should be performed in the preoperative diagnosis of salivary gland lesions as it offers high diagnostic accuracy and specificity and an acceptable sensitivity. However the following recommendations may be made:

$>$ Multiple passes from multiple sites should be done and adequacy of smears checked in the FNA room itself, if possible. Interpreting hypocellular smears should be avoided.

$>$ An experienced cytopathologist should review all the cytology slides and difficult cases should be discussed with panel. 


\section{ORIGINAL ARTICLE}

$>$ Since high rate of false negative in FNAC is a problem, therefore, while FNAC is negative in case of clinically suspicious mass, it is suggested to perform excision of the mass with frozen section biopsy.

$>$ Oil immersion lens should be used to detect subtle atypia to avoid the chance of missing malignant lesion.

\section{REFERENCES:}

1. Tilak V, Dhaded AV, Jain R. Fine needle aspiration cytology of head and neck masses. Indian J Pathol Microbiol 2002; 45(1): 23-30.

2. Noor ul Aan, Tanwani AK. Pitfalls in Salivary Gland Fine-Needle Aspiration Cytology. International Journal of Pathology; 2009; 7(2): 61.

3. Orell SR. Diagnostic difficulty in the interpretation of FNA of salivary lesions. Cytopathol. 1995, 6: 285-300.

4. Eneroth CM, Zajicek J. Aspiration biopsy of salivary gland tumors III. Morphological studies on smears and histologic section from 368 mixed tumors. Acta Cytol. 1966; 10:440-454.

5. Stramandinoli RT, Sassi LM et al. Accuracy, sensitivity and specificity of fine needle aspiration biopsy in salivary gland tumours: A retrospective study. Med Oral Patol Oral Cir Bucal. 2010 Jan 1; 15 (1):e32-7.

6. Koss LG, Melamed MR. Salivary glands. In: Diagnostic cytology \& its histopathologic bases. 5th ed. Pheladilphia. Lippincott Williams \& Wilkins. 2006, 1230-60.

7. Cajulis R, Gokaslan S, Gordon H, Frais-Hidvegi D. Fine needle aspiration biopsy of the salivary glands. Acta Cytol. 1997, 41: 1412-20.

8. Klijanienko J. Head and neck; salivary gland; Chapter 4. In: Fine needle aspiration cytology. Orell SR, Sterrett GF, Whitaker D., editors. New Delhi: Elsevier; 2005; 57-60.

9. Abrari A, Ahmed S, Baksh V. Cytology in the oto-rhinolaryngologist's domain, a study of 150 cases, emphasizing diagnostic utility and pitfalls. Indian J Otolaryngol Head \& Neck Surg. 2002, 54: 107-10.

10. Elagoz SY, Gulluoglu MG, Imazbayhan DW, Ozer HS. The value of fine-needle aspiration cytology in salivary gland lesions. J Otolaryngol Head \& Neck Surg. 2007, 69: 51-56.

11. Stewart CJ, MacKenzie K, McGarry GW et al. Fine-needle aspiration cytology of salivary gland: a review of 341 cases. Diagn Cytopathol. 2000; 22:139-146.

12. Akhter J, Hirachand S, Lakhey M. Role of FNAC in the diagnosis of salivary gland swellings. Kathmandu Univ Med J (KUMJ). 2008, 6: 204-8.

13. Balakrishnan K, Castling B, McMahon J et al. Fine needle aspiration cytology in the management of a parotid mass: A two center retrospective. Surgeon. 2005;3:67-72.

14. Orell SR. Diagnostic difficulties in the interpretation of fine needle aspirates of salivary gland lesions: the problem revisited. Cytopathology. 1995; 6:285-300.

15. Ezzat N, Tahoun N. Diagnostic Accuracy and Pitfalls of Preoperative Fine Needle Aspiration Cytology in Salivary Gland Lesions. Journal of the Egyptian Nat. Cancer Inst., 2008; 20(4):358-368. 
TABLE 1: Distribution of cases according to the cytological evaluation $(n=60)$.

\begin{tabular}{|l|l|}
\hline CYTOLOGICAL DIAGNOSIS & NUMBER OF CASES $(\mathbf{n = 6 0 )}$ \\
\hline NON NEOPLASTIC & \\
\hline Chronic sialadenitis & 10 \\
\hline Retention Cyst & 5 \\
\hline BENIGN & \\
\hline Pleomorphic adenoma & 26 \\
\hline Benign neoplastic lesion & 5 \\
\hline Lipoma & 1 \\
\hline Schwannoma & 1 \\
\hline MALIGNANT & \\
\hline Adenoid cystic carcinoma & 6 \\
\hline Acinic cell carcinoma & 4 \\
\hline Mucoepidermoid carcinoma & 2 \\
\hline
\end{tabular}

TABLE 2: Comparative analysis of data obtained in this study with similar previous studies.

\begin{tabular}{|l|l|l|l|}
\hline STUDIES & SENSITIVITY & SPECIFICITY & ACCURACY \\
\hline Eneroth et al (1967) & 64 & 95 & 89 \\
\hline Orell (1995) & 85 & 99 & 94 \\
\hline Stramandinoli RT et al (2010) & 68.2 & 87.7 & 82.3 \\
\hline PRESENT STUDY & 69.5 & 92.8 & 84 \\
\hline
\end{tabular}

TABLE 3: Six (06) FNAC cases of discordant diagnoses in specific typing of the lesion

\begin{tabular}{|c|c|c|c|c|}
\hline CASES & $\begin{array}{l}\text { AGE (yrs) } \\
\text { and SEX }\end{array}$ & $\begin{array}{ll}\text { SITE } & \text { OF } \\
\text { ASPIRATION } & \end{array}$ & $\begin{array}{l}\text { CYTOLOGICAL } \\
\text { DIAGNOSIS }\end{array}$ & $\begin{array}{l}\text { HISTOLOGICAL } \\
\text { DIAGNOSIS }\end{array}$ \\
\hline 1. & 43, Male & Parotid & $\begin{array}{l}\text { Pleomorphic } \\
\text { adenoma }\end{array}$ & $\begin{array}{l}\text { Adenoid } \quad \text { cystic } \\
\text { carcinoma }\end{array}$ \\
\hline 2. & 48, Male & Parotid & $\begin{array}{l}\text { Pleomorphic } \\
\text { adenoma }\end{array}$ & $\begin{array}{l}\text { Adenoid } \quad \text { cystic } \\
\text { carcinoma }\end{array}$ \\
\hline 3. & 35, Male & Parotid & $\begin{array}{l}\text { Benign neoplastic } \\
\text { lesion }\end{array}$ & $\begin{array}{ll}\text { Acinic } & \text { cell } \\
\text { carcinoma } & \\
\end{array}$ \\
\hline 4. & 46, Male & Parotid & $\begin{array}{l}\text { Benign neoplastic } \\
\text { lesion }\end{array}$ & $\begin{array}{ll}\text { Acinic } & \text { cell } \\
\text { carcinoma } & \\
\end{array}$ \\
\hline 5. & 59, Male & & $\begin{array}{l}\text { Adenoid } \quad \text { cystic } \\
\text { carcinoma }\end{array}$ & $\begin{array}{l}\text { Pleomorphic } \\
\text { adenoma }\end{array}$ \\
\hline 6. & 49 , Male & Parotid & $\begin{array}{l}\text { Mucoepidermoid } \\
\text { carcinoma }\end{array}$ & $\begin{array}{l}\text { Mucus retention } \\
\text { cyst }\end{array}$ \\
\hline
\end{tabular}




\section{ORIGINAL ARTICLE}

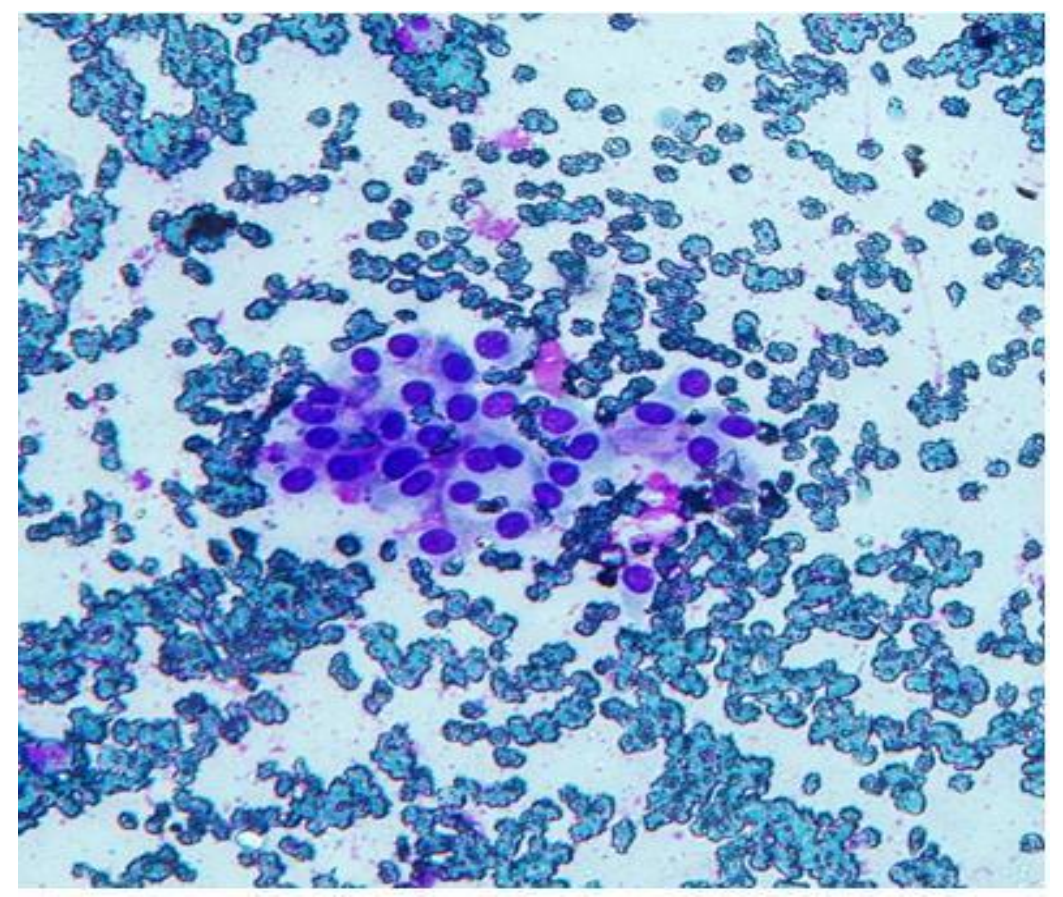

FIGURE 1: Case of adenoid cystic carcinoma misdiagnosed as pleomorphic adenoma on cytology (MGG, $100 \mathrm{X}$ )

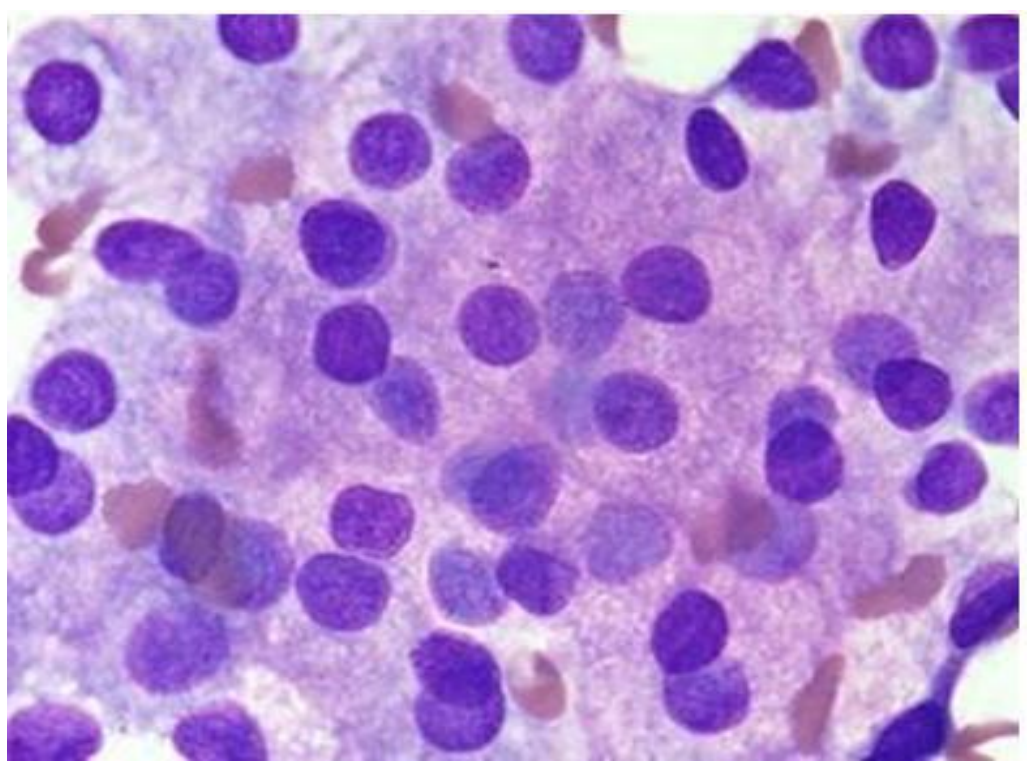

FIGURE 2: Case of acinic cell carcinoma misdiagnosed as benign neoplastic lesion (MGG, 400x) 


\section{ORIGINAL ARTICLE}

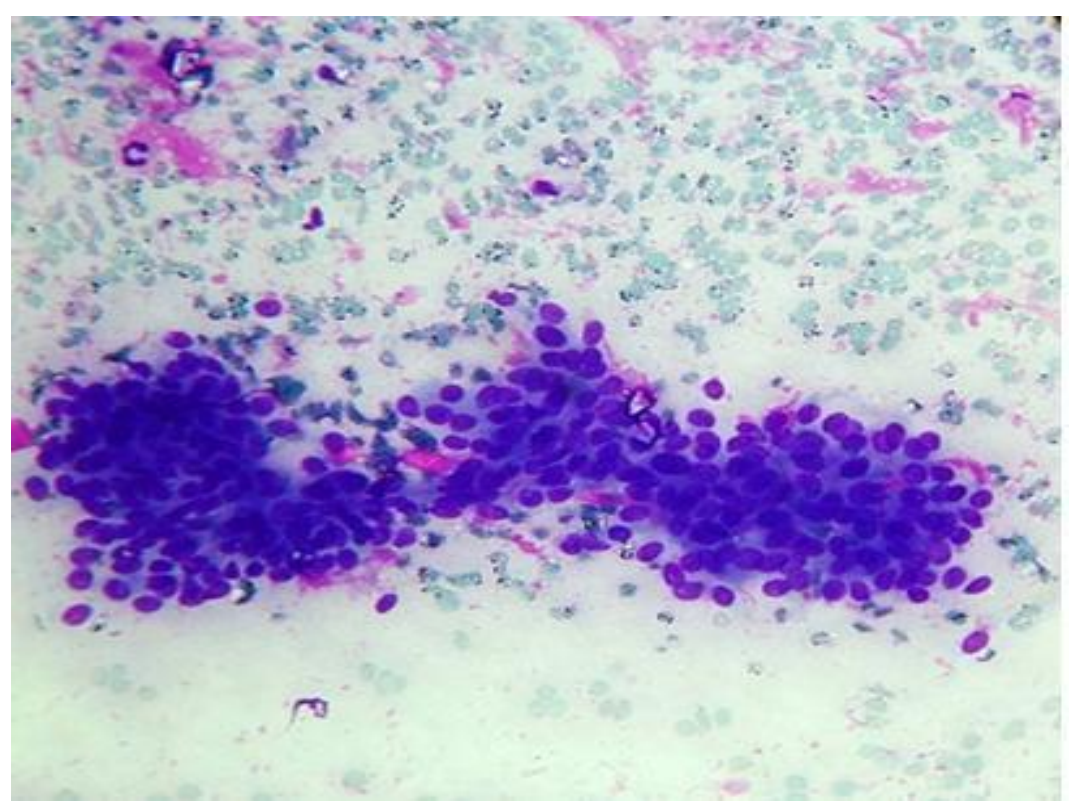

FIGURE 3: Case of pleomorphic adenoma over diagnosed as adenoid cystic carcinoma (MGG, 100X)

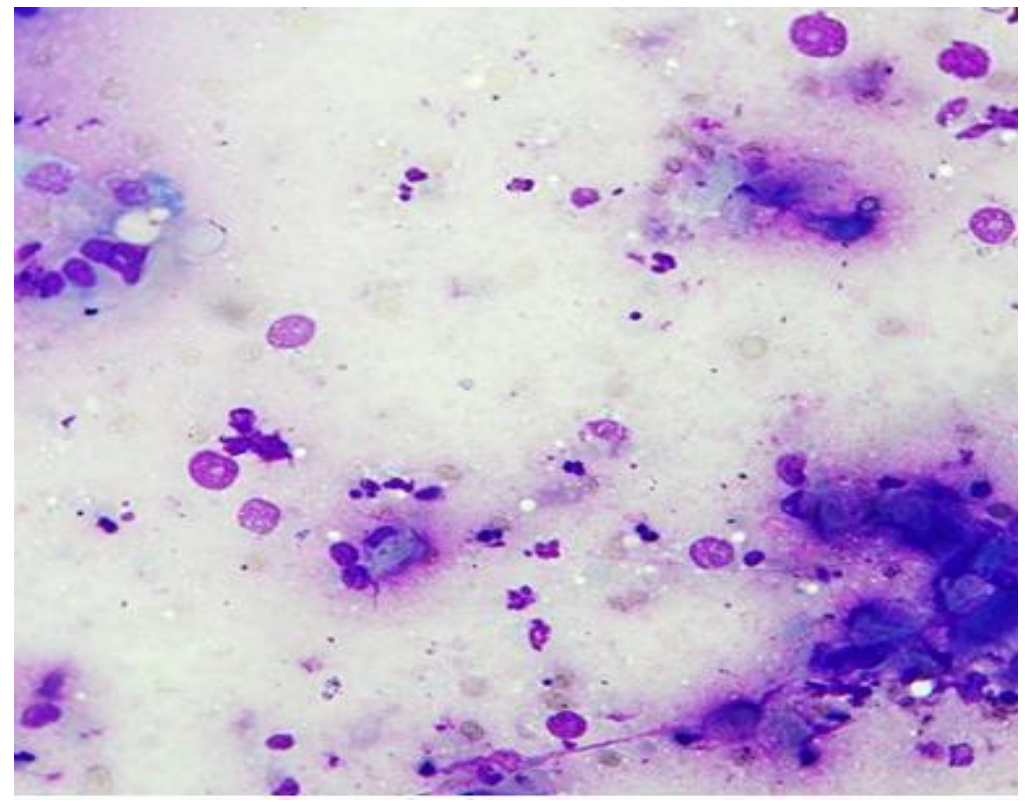

FIGURE 4: Case of mucus retention cyst misdiagnosed as mucoepidermoid carcinoma on cytology (MGG, 400X) 